\title{
Enxertos vasculares homólogos e heterólogos conservados em glicerina na fleboplastia da jugular em eqüinos
}

[Arterial homograft and venous heterograft conserved in glycerin in the phleboplasty of the jugular in equines]

\author{
D.R. Stainki ${ }^{1}$, G.E.S. Alves ${ }^{2}$, A.C. Vasconcelos ${ }^{3}$, M.P. Barbosa ${ }^{4}$, H.P. Oliveira ${ }^{2}$ \\ ${ }^{1}$ Faculdade de Zootecnia, Veterinária e Agronomia - Pontifícia Universidade Católica do Rio Grande do Sul \\ BR $472 \mathrm{~km} 07$ \\ 97500-970 - Uruguaiana, RS \\ ${ }^{2}$ Escola de Veterinária da UFMG - Belo Horizonte, MG \\ ${ }^{3}$ Instituto de Ciências Biológicas da UFMG - Belo Horizonte, MG \\ ${ }^{4}$ Escola de Engenharia da UFMG - Belo Horizonte, MG
}

\begin{abstract}
RESUMO
Doze eqüinos foram divididos aleatoriamente em dois grupos de seis animais (grupos I e II), com a finalidade de estudar a compatibilidade tecidual e a propriedade de indução de trombos de dois tecidos biológicos conservados em glicerina a $98 \%$. Esses tecidos foram usados na restauração da jugular externa e se constituíram de artéria carótida comum homóloga (ACCHo), no grupo I, e veia jugular externa heteróloga (VJEHe), no grupo II. Para a restauração, utilizaram-se duas técnicas de anastomose da jugular, sendo, no grupo I, a técnica de bypass e, no grupo II, a substituição de um segmento da jugular esquerda por meio de anastomose vascular término-terminal. Para avaliar a trombogênese local e a histocompatibilidade, foram realizados exames clínicos, hematológicos, ecoDopplercardiográficos e histológicos dos segmentos vasculares enxertados. Os segmentos foram colhidos após 45 dias da avaliação pós-operatória, tendo a jugular direita como testemunha para os exames histológicos. Ambos os tecidos foram compatíveis quando implantados nos eqüinos, sem processo inflamatório acentuado, indicativo de rejeição. A técnica de bypass não foi eficiente na restauração da jugular, ocorrendo trombose obliterante dos enxertos de ACCHo. A substituição completa do segmento da jugular por VJEHe pode ser viável para o restabelecimento do fluxo sangüíneo da jugular de eqüinos, desde que se mantenha a igualdade dos diâmetros entre o enxerto e o vaso receptor.
\end{abstract}

Palavras-chave: eqüino, tecido biológico, glicerina, cirurgia vascular, enxerto

\begin{abstract}
Twelve horses were randomly divided into two groups of six animals each (groups I and II) in order to study the compatibility and trombogenicity of two biological tissues conserved in glycerin at $98 \%$ which were used to restore the external jugular. The tissues consisted of arterial homograft - ACCHo (group I) and venous heterograft - VJEHe (group II). Two different techniques for jugular anastomosis were performed - bypass in group I and replacement of a segment of the left jugular by means of end to end vascular anastomosis in group II. Clinical, hematological, Doppler ultrasonography, and histological examinations of the grafted vascular segments were conducted to evaluate local trombogenicity and tissue compatibility. All animals had the segments collected after 45 days, being the right jugular used as standard for the histopathological exams. Both tissues were compatible since no serious inflammatory process indicative of rejection took place. The bypass technique was not efficient for jugular restoration because of the occurrence of obliterant trombosys of the ACCHo. The full replacement of a jugular
\end{abstract}

Recebido para publicação em 13 de março de 2003

Recebido para publicação, após modificações, em 21 de setembro de 2004

E-mail: drstainki@uol.com.br 
segment by the VJEHe can be feasible in reestablishing blood flow through the jugular of horses as long as the diameters of the grafted tissue and the original blood vessel are kept the same.

Keywords: horse, biological tissues, glycerin, vascular surgery, graft

\section{INTRODUÇÃO}

A trombose da jugular é uma condição comumente encontrada nos eqüinos (Hay, 1998) e decorre de diversas etiologias secundárias às venipunções, medicações intravenosas e cateterizações vasculares, principalmente nos eqüinos com endotoxemia ou coagulação intravascular disseminada (Marr e Reef, 1995). Existe relação entre a tromboflebite e as propriedades físico-químicas trombogênicas do material utilizado na confecção de cateteres venosos (Bayly e Vale, 1982; Spurlock et al., 1990; Hay, 1992).

Os principais fatores etiopatogênicos são as lesões na parede vascular, o estado de hipercoagulação e a estase sangüínea (Moore e Hinchcliff, 1994). Das lesões trombogênicas do endotélio vascular, a de maior ocorrência é a provocada pelo trauma mecânico (Slauson e Cooper, 1990), que se inicia com a formação da rede de fibrina nos locais da perfuração da veia e de contato da extremidade do cateter com o endotélio vascular (Bayly e Vale, 1982).

Os principais aparelhos utilizados para o diagnóstico clínico da tromboflebite jugular são o ultra-som (Gardner et al., 1991) e o ecoDoppler (Rijkenhuizen e Van Swieten, 1998). Os exames ultra-sonográficos são úteis na caracterização e diferenciação dos trombos com relação ao edema perivascular (Marr e Reef, 1995).

A jugular é utilizada como modelo para o estudo de próteses vasculares nos eqüinos. Vários materiais são usados para a reconstrução vascular no homem e em pequenos animais. A despeito do aperfeiçoamento na confecção dos materiais, a freqüência elevada de trombose no sítio cirúrgico é ainda preocupante (Hay, 1998).

O objetivo do trabalho foi avaliar a trombogenicidade e a biocompatibilidade da artéria carótida comum homóloga (ACCHo) e da veia jugular externa heteróloga (VJEHe), preservadas em glicerina, empregadas com duas técnicas de fleboplastia para reconstrução vascular na espécie eqüina.

\section{MATERIAL E MÉTODOS}

Utilizaram-se 12 eqüinos sem raça definida, seis machos (dois não castrados e quatro castrados) e seis fêmeas. O escore corporal, conforme Speirs (1999), variou de 2 (moderado) a 3 (bom).

Os animais, com pesos entre 210 e $340 \mathrm{~kg}$, foram desverminados com ivermectina ${ }^{1}$ na dose de $200 \mathrm{mcg} / \mathrm{kg}$, banhados com carrapaticida (deltametrina $^{2}$ ) e mantidos em piquete. A dieta se constituiu de ração comercial $^{3}$, feno de capim coast-cross (Cynodon deactylon) e água ad libitum.

Durante 24 horas, no período pré-operatório, os eqüinos foram mantidos em jejum de sólidos e em baias isoladas. No período pós-operatório, permaneceram 10 dias em cocheiras, onde receberam a mesma dieta, após o que foram removidos os pontos de pele e mantidos em piquete.

Os eqüinos foram divididos em dois grupos (I e II) de seis animais, com três fêmeas e três machos cada. Todos foram submetidos à fleboplastia da jugular esquerda por meio de enxertos vasculares de ACCHo (grupo I) e de VJEHe (grupo II) e mantidos em observação pós-operatória durante 45 dias.

Os eqüinos do grupo I foram submetidos à obstrução da jugular com pontos de ligadura. $\mathrm{O}$ fluxo sangüíneo foi desviado por meio de bypass constituído por ACCHo, medindo $10 \mathrm{~cm}$ de comprimento. Nos do grupo II, um segmento de 8 a $11 \mathrm{~cm}$ de comprimento da veia jugular externa foi substituído por VJEHe, com anastomose término-terminal.

${ }^{1}$ Eqvalan - Merial - Campinas/SP - Brasil.

${ }^{2}$ Butox - Químio S.A. - São Paulo/SP - Brasil.

${ }^{3}$ Nutiage 12 - Guabi, Mogiana Alimentos S/A. - São

Paulo/SP - Brasil. 
Após incisão longitudinal de aproximadamente $20 \mathrm{~cm}$ na pele, centralizada no terço médio cervical, dissecou-se um segmento da jugular externa esquerda, entre os músculos cleidomastódeo e esternomandibular, promovendo a ligadura dos seus ramos anastomóticos locais com fio de seda 2-0 $0^{4}$.

No grupo I, após a exposição da jugular externa esquerda, fez-se o bloqueio parcial do fluxo sangüíneo em dois pontos por meio de pinças Satinsky, com a distância de $10 \mathrm{~cm}$ entre os locais de pinçamento. Com bisturi e tesoura de íris, procedeu-se a flebotomia longitudinal cranial e caudal, de aproximadamente um centímetro, no segmento vascular apreendido pelas pinças. As bordas da flebotomia cranial foram suturadas ao enxerto de ACCHo de forma término-lateral, atravessando todas as camadas dos vasos. $\mathrm{O}$ fio utilizado para a sutura vascular foi $o$ polipropileno $5-0^{5}$. O mesmo procedimento de anastomose foi realizado na flebotomia caudal. Após o término das anastomoses, as pinças Satinsky foram removidas, promovendo-se a obstrução do fluxo da jugular com dois pontos de ligadura (fio de seda 2-0), distanciados a um centímetro das anastomoses, desviando por completo o fluxo sangüíneo para o enxerto.

No grupo II, após dissecação da jugular e ligadura dos ramos anastomóticos, foram colocados dois clampes Buldog Potts, limitando um segmento de aproximadamente $15 \mathrm{~cm}$ (terço médio), obstruindo totalmente seu fluxo sangüíneo. Procedeu-se, a seguir, uma flebectomia da jugular, de aproximadamente $5 \mathrm{~cm}$, com tesoura de íris. O procedimento de anastomose término-terminal entre o enxerto e a jugular seguiu a técnica da triangulação, segundo Carrel citado por Archibald et al. (1980), utilizando-se fio prolene 5-0 e penetrando todas as camadas das paredes dos vasos. Após o término da anastomose, foram liberados os clampes Buldog Potts para o restabelecimento do fluxo sangüíneo.

No pós-operatório, foram realizadas três aplicações de heparina sódica $^{6}$, na dose de $50 \mathrm{UI} / \mathrm{kg} / \mathrm{SC}$, a primeira no pós-operatório

\footnotetext{
${ }^{4}$ Fio de seda n ${ }^{\mathrm{O}}$ 2-0 - Ethicon - São José dos Campos/SP Brasil.

${ }^{5}$ Prolene 5-0 - Ethicon - São José dos Campos/SP- Brasil.

${ }^{6}$ Liquemine - Laboratório Roche Química e Farmeceutica S/A. - Rio de Janeiro/RJ- Brasil.
}

imediato e as demais 24 e 48 horas após. Todos os eqüinos receberam três aplicações de benzilpenicilina potássica ${ }^{7}$, na dose de $22.000 \mathrm{UI} / \mathrm{kg} / \mathrm{IM}$ de peso vivo, a cada 24 horas, sendo a primeira aplicação imediatamente após a cirurgia. A terapia antiinflamatória constou de três aplicações de fenilbutazona ${ }^{8}$, na dose de $4 \mathrm{mg} / \mathrm{kg} / \mathrm{IV}$, a cada 24 horas, a primeira aplicação logo após a cirurgia.

Todos os eqüinos foram submetidos a exames complementares para avaliação dos segmentos enxertados por meio de exame clínico, de ecoDoppler, de ultra-sonografia e pela avaliação do hemograma, das concentrações de fibrinogênio e das proteínas totais. Ao final do período de exames pós-operatórios, os segmentos vasculares operados e a jugular direita (testemunha) foram colhidos e submetidos à microscopia óptica para avaliar as alterações morfológicas e a morfometria por meio de sistema analisador de imagens.

O teste clínico pós-operatório de patência dos enxertos baseou-se no ingurgitamento da jugular por compressão digital sobre o segmento vascular caudal ao enxerto, observando-se imediato ingurgitamento nos segmentos caudal, local cranial e nos enxertos que permaneceram patentes.

Para os exames ecográficos, utilizou-se um ecoDoppler $^{9}$ nos modos bidimensional e Doppler. No modo Doppler, observou-se o mapeamento por fluxo a cores e pulsado. O transdutor empregado foi de $7,5 \mathrm{MHz}$ setorial mecânico. Este equipamento nos eqüinos do grupo I, no pré e pós-operatório, foi utilizado para estimar o diâmetro de lume vascular, a espessura de parede vascular e o mapeamento de fluxo colorido em tomada longitudinal, para avaliar a presença ou a formação de trombos.

Realizou-se a ultra-sonografia ${ }^{10}$ nos animais do grupo II para a verificação pré e pós-operatória do diâmetro de luz do vaso ingurgitado, da

\footnotetext{
${ }^{7}$ Novapen - Marcolab Laboratórios S.A. - Rio de Janeiro/RJ - Brasil.

${ }^{8}$ Equipalazone - Marcolab Laboratórios S.A. - Rio de Janeiro/RJ - Brasil.

${ }^{9}$ Hewlett Packard (HP) - Sonos 100 CF., Al. Rio Negro, 750

- Barueri, São Paulo - Brasil.

${ }^{10}$ Ultra-som Medison , Eureka AS-600 - Transdutor 7,5 MHz e impressora Sony / UP-890 - São Paulo/SP-Brasil.
} 
espessura de parede vascular e para avaliar a presença ou a formação de trombos. Os dados foram obtidos em três áreas na região cervical esquerda - jugular cranial, média (região do enxerto) e caudal, com uma avaliação préoperatória e aos $5,10,20,30$ e 40 dias de pósoperatório.

As amostras de sangue foram colhidas durante o período pré-operatório e aos 10 e 30 dias de pósoperatório, por venipunção jugular direita, para a realização de hemograma, de fibrinogênio sangüíneo e de proteínas totais.

Os animais foram submetidos a eutanásia no $45^{\circ}$ dia do pós-operatório, colhendo-se a região do enxerto vascular e a jugular direita. Colheram-se amostras das seguintes áreas: jugular cranial ao enxerto ( $\mathrm{JCr}$ ), região da anastomose procimal $(\mathrm{EP})$, região média do enxerto $(\mathrm{EM})$, região da anastomose distal (ED) e jugular caudal ao enxerto ( $\mathrm{JCd})$ Os tecidos foram fixados em formol tamponado a $10 \%$ e processados segundo técnica rotineira para inclusão em parafina.

As lâminas foram examinadas ao microscópico óptico para a identificação e caracterização das lesões, sendo posteriormente submetidas à análise morfométrica em sistema analisador de imagens Kontron Elektronic GMBH e programa $\mathrm{KS} 300$ v $2.0^{11}$.

Para obtenção dos dados histológicos, foram analisados campo inflamatório, área de colágeno e presença e morfometria de trombos (Fig. 1).

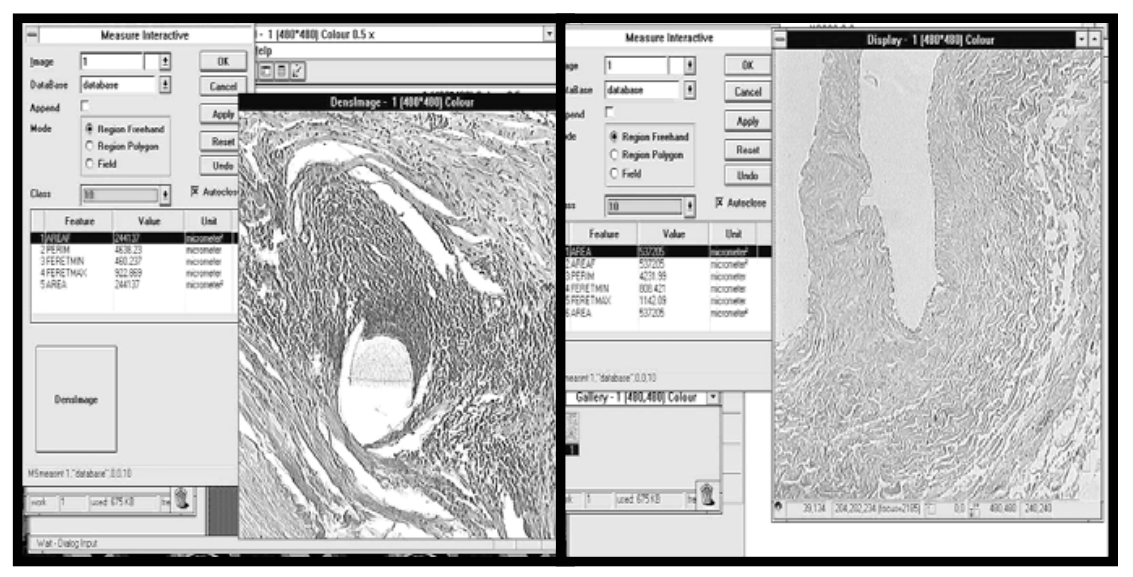

Figura 1. Determinação do campo inflamatório e área de colágeno nas regiões de anastomose proximal e distal dos enxertos vasculares.

Utilizou-se o pacote estatístico SAS (User's... 1997), comparando-se os resultados histológicos referentes aos enxertos ACCHo e VJEHe, considerando-se a reação inflamatória, a área de colágeno e a trombogênese por grupo. Os dados foram submetidos a análise de variância e as médias comparadas pelo teste $t$ de Student.

\section{RESULTADOS}

Dois animais apresentaram deiscência parcial dos pontos de pele, que foi controlada com limpeza diária do ferimento. Dois animais apresentaram edema acentuado e seroma na região cervical ventro-lateral esquerda, que perdurou de cinco a 10 dias.

\footnotetext{
${ }^{11}$ Analisador de imagens Kotron Eletoronic GMBH / KS 300 - versão 2.0 - São Paulo/SP - Brasil.
} 
No pós-operatório imediato, cinco eqüinos do grupo I apresentaram ingurgitamento da jugular na região cranial ao implante vascular, acompanhado de edema localizado no músculo masseter e glândula parótida. $\mathrm{O}$ processo progrediu para tromboflebite com enrijecimento da parede da jugular no sentido cranial ao enxerto.

$\mathrm{O}$ eqüino do grupo I que não apresentou as alterações hemodinâmicas localizadas permaneceu positivo ao teste de ingurgitamento da jugular durante todo o período de observação pós-operatório. No grupo II, metade dos eqüinos foi positiva ao teste de ingurgitamento durante o período de observação; os demais diminuiram gradativamente a capacidade de ingurgitar e em torno de 10 dias já não respondiam ao teste, indicando ausência total de fluxo.

Somente um eqüino do grupo II evidenciou discreta leucocitose durante o pré e pósoperatório. Os demais permaneceram dentro dos limites fisiológicos.

Os resultados dos exames bioquímicos das concentrações de proteínas totais (PT) e de fibrinogênio sangüíneo (FB) encontram-se na Tab. 1. A razão entre as proteínas totais e o fibrinogênio (PT/FB) está citada na Tab. 2.

Tabela 1. Valores da bioquímica sangüínea de eqüinos no período pré-operatório e aos 10 e 30 dias de pós-operatório

\begin{tabular}{|c|c|c|c|c|c|c|c|}
\hline \multirow{2}{*}{ Grupo } & \multirow[t]{2}{*}{ Animal } & \multicolumn{2}{|c|}{ Pré-operatório } & \multicolumn{2}{|c|}{10 dias } & \multicolumn{2}{|c|}{30 dias } \\
\hline & & PT g/dL & FB mg/dL & PT g/dL & $\mathrm{FB} \mathrm{mg} / \mathrm{dL}$ & PT g/dL & $\mathrm{FB} \mathrm{mg} / \mathrm{dL}$ \\
\hline \multirow{6}{*}{ I } & Ia & 8,2 & 400 & 8,6 & 400 & 7,2 & 200 \\
\hline & $\mathrm{Ib}$ & 9,0 & 400 & 8,8 & 600 & 7,2 & 200 \\
\hline & Ic & 8,8 & 600 & 9,0 & 400 & 7,0 & 200 \\
\hline & Id & 9,0 & 300 & 7,8 & 300 & 7,8 & 400 \\
\hline & Ie & 7,2 & 600 & 7,0 & 400 & 7,0 & 400 \\
\hline & If & 8,4 & 200 & 7,8 & 400 & 8,2 & 200 \\
\hline \multirow{6}{*}{ II } & IIa & 7,0 & 400 & 7,4 & 200 & 7,6 & 200 \\
\hline & $\mathrm{IIb}$ & 6,0 & 300 & 6,0 & 400 & 6,0 & 400 \\
\hline & IIc & 7,5 & 300 & 7,4 & 400 & 8,4 & 400 \\
\hline & IId & 7,8 & 400 & 7,6 & 400 & 7,1 & 300 \\
\hline & IIe & 7,0 & 500 & 6,6 & 400 & 7,9 & 320 \\
\hline & IIf & 7,1 & 100 & 7,3 & 300 & 8,4 & 400 \\
\hline
\end{tabular}

$\overline{\mathrm{PT}}=$ proteínas plasmáticas totais; $\mathrm{FB}=$ fibrinogênio

Grupo I: enxerto vascular da artéria carótida comum homóloga; grupo II: enxerto vascular da veia jugular externa heteróloga.

Tabela 2. Comparação dos valores da razão proteínas totais/fibrinogênio (PT/FB) dos eqüinos nos diferentes períodos de colheita

\begin{tabular}{|c|c|c|c|c|}
\hline \multirow{2}{*}{ Grupo } & \multirow{2}{*}{ Animal } & \multirow{2}{*}{$\begin{array}{l}\text { Razão PT/FB } \\
\text { Pré-operatório }\end{array}$} & \multirow{2}{*}{$\begin{array}{c}\text { Razão PT/FB } \\
10 \text { dias } \\
\end{array}$} & \multirow{2}{*}{$\begin{array}{c}\text { Razão PT/FB } \\
30 \text { dias } \\
\end{array}$} \\
\hline & & & & \\
\hline \multirow{6}{*}{ I } & Ia & 19,5 & 20,5 & 35,0 \\
\hline & $\mathrm{Ib}$ & 21,5 & 13,6 & 35,0 \\
\hline & Ic & 13,6 & 21,5 & 34,0 \\
\hline & Id & 29,0 & 25,0 & 18,5 \\
\hline & Ie & 11,0 & 16,5 & 16,5 \\
\hline & If & 41,0 & 18,5 & 40,0 \\
\hline \multirow{6}{*}{ II } & IIa & 16,5 & 36,0 & 37,0 \\
\hline & $\mathrm{IIb}$ & 19,0 & 14,0 & 14,0 \\
\hline & IIc & 24,0 & 17,5 & 20,0 \\
\hline & IId & 18,5 & 18,0 & 22,6 \\
\hline & IIe & 13,0 & 15,5 & 25,3 \\
\hline & IIf & 70,0 & 23,3 & 20,0 \\
\hline
\end{tabular}

$\mathrm{PT}=$ proteínas plasmáticas totais, $\mathrm{FB}$ - fibrinogênio.

Grupo I: enxerto vascular da artéria carótida comum homóloga; grupo II: enxerto vascular da veia jugular externa heteróloga.
A análise ecográfica da trombogênese encontrase descrita na Tab. 3. Observou-se que a organização laminar do trombo aumentou sua ecogenicidade, permitindo a observação das linhas de Zahn. Os eqüinos do grupo I apresentaram trombos oclusivos na luz do enxerto e semi-oclusivos na jugular cranial ao mesmo.

Em cinco eqüinos do grupo $\mathrm{I}$, o segmento vascular enxertado encontrava-se englobado por tecido fibrótico que dificultava a diferenciação e dissecação das demais estruturas. No grupo II, cinco eqüinos evidenciaram uma fina camada de tecido fibrótico, de fácil dissecação, sobre o enxerto vascular. 
Enxertos vasculares homólogos e heterólogos...

Tabela 3. Valores da análise ultra-sonográfica da trombogênese no enxerto vascular, nos diferentes tempos de observação no pós-operatório

\begin{tabular}{|c|c|c|c|c|c|c|c|c|c|c|}
\hline \multirow[b]{2}{*}{ Animal } & \multicolumn{2}{|c|}{5 dias } & \multicolumn{2}{|c|}{10 dias } & \multicolumn{2}{|c|}{20 dias } & \multicolumn{2}{|c|}{30 dias } & \multicolumn{2}{|c|}{40 dias } \\
\hline & $\begin{array}{l}\text { Número e } \\
\text { dimensão }\end{array}$ & Localização & $\begin{array}{l}\text { Número e } \\
\text { dimensão }\end{array}$ & Localização & $\begin{array}{l}\text { Número e } \\
\text { dimensão }\end{array}$ & Localização & $\begin{array}{l}\text { Número e } \\
\text { dimensão }\end{array}$ & Localização & $\begin{array}{l}\text { Número e } \\
\text { dimensão }\end{array}$ & Localização \\
\hline IIa & $\begin{array}{l}1 \text { trombo } \\
3,6 \mathrm{~mm}\end{array}$ & $\begin{array}{l}\text { Terço } \\
\text { médio }\end{array}$ & $\begin{array}{c}3 \text { trombos } \\
1,3,1,6 \mathrm{e} \\
3,9 \mathrm{~mm}\end{array}$ & $\begin{array}{l}\text { Terço } \\
\text { médio }\end{array}$ & $\begin{array}{c}3 \text { trombos } \\
1,3,1,6 \mathrm{e} \\
3,9 \mathrm{~mm}\end{array}$ & $\begin{array}{l}\text { Terço } \\
\text { médio }\end{array}$ & $\begin{array}{c}3 \text { trombos } \\
1,3,1,6 \mathrm{e} \\
3,9 \mathrm{~mm}\end{array}$ & $\begin{array}{l}\text { Terço } \\
\text { médio }\end{array}$ & $\begin{array}{c}3 \text { trombos } \\
1,3,1,6 \mathrm{e} \\
3,9 \mathrm{~mm}\end{array}$ & $\begin{array}{l}\text { Terço } \\
\text { médio }\end{array}$ \\
\hline IIb & $\begin{array}{c}2 \text { trombos } \\
1,1 \mathrm{e} \\
1,6 \mathrm{~mm}\end{array}$ & $\begin{array}{c}\text { Terço } \\
\text { proximal }\end{array}$ & $\begin{array}{l}1 \text { trombo } \\
0,16 \mathrm{~mm}\end{array}$ & $\begin{array}{c}\text { Terço } \\
\text { proximal }\end{array}$ & - & NL & - & NL & - & NL \\
\hline IIc & - & NL & $\begin{array}{c}1 \text { trombo } \\
1,6 \mathrm{~mm}\end{array}$ & $\begin{array}{c}\text { Terço } \\
\text { proximal }\end{array}$ & $\begin{array}{c}2 \text { trombos } \\
2,0 \mathrm{e} \\
3,0 \mathrm{~mm}\end{array}$ & $\begin{array}{c}\text { Terço } \\
\text { proximal }\end{array}$ & - & OVT & - & OVT \\
\hline IId & $\begin{array}{l}1 \text { trombo } \\
2,0 \mathrm{~mm}\end{array}$ & $\begin{array}{c}\text { Terço } \\
\text { proximal }\end{array}$ & $\begin{array}{l}1 \text { trombo } \\
2,0 \mathrm{~mm}\end{array}$ & $\begin{array}{c}\text { Terço } \\
\text { proximal }\end{array}$ & $\begin{array}{l}1 \text { trombo } \\
2,1 \mathrm{~mm}\end{array}$ & $\begin{array}{c}\text { Terço } \\
\text { proximal }\end{array}$ & - & NL & $\begin{array}{l}1 \text { trombo } \\
4,0 \mathrm{~mm}\end{array}$ & $\begin{array}{l}\text { Terço } \\
\text { médio }\end{array}$ \\
\hline IIe & - & OVT & - & OVT & - & OVT & - & OVT & - & OVT \\
\hline IIf & - & OVT & - & OVT & - & OVT & - & OVT & - & OVT \\
\hline
\end{tabular}

$\mathrm{Na}$ avaliação da trombogênese, obteve-se significância entre os animais do grupo I quanto à medida de área. No segmento da jugular cranial, a área e o perímetro dos trombos apresentaram-se significativamente maiores em relação aos demais segmentos estudados. O segmento de enxerto médio apresentou a menor média, porém não houve diferença entre os segmentos de enxerto proximal e enxerto distal.

A maior média de diâmetro mínimo dos trombos foi evidenciada no segmento da jugular cranial, que apresentou diferença significativa em relação aos demais segmentos do tecido enxertado.

O diâmetro máximo dos trombos evidenciou diferenças significativas entre os eqüinos do grupo I. O segmento da jugular cranial foi o de maior evidência quanto ao diâmetro máximo de trombo e apresentou diferença significativa em relação aos demais segmentos. $\mathrm{O}$ diâmetro máximo de trombo apresentou diferença significativa entre os eqüinos do grupo II. A maior média de diâmetro máximo evidenciado foi no segmento enxerto médio, sem diferença estatística com os segmentos enxerto distal e jugular cranial, mas com diferença significativa ao ser comparado com o segmento enxerto proximal.

\section{DISCUSSÃO}

O ingurgitamento acentuado da jugular na porção cranial ao implante, na técnica de bypass (grupo
I), foi atribuído à obstrução do segmento de ACCHo por trombos. Isso resultou em estase do fluxo sangüíneo no vaso e formação de flebotrombose e flebite. A estase sangüínea foi citada por Moore e Hinchcliff (1994) como um dos fenômenos locais de maior importância na patogenia da tromboflebite, juntamente com as lesões de parede vascular e os estados de hipercoagulação. Rijkenhuizen e Van Swieten (1998) consideraram que a formação de edema na região da parótida e do masseter decorre da hipertensão desenvolvida pela hiperemia passiva em decorrência da trombose na jugular. No grupo I, o edema, que ocorreu durante o pósoperatório imediato, foi devido à hipertensão local decorrente da redução do fluxo sangüíneo pelo estreitamento abrupto que se deu no lume vascular do enxerto de ACCHo, seguida de hiperemia passiva e hipertensão na jugular cranial ao trombo.

Os eqüinos receptores de VJEHe (grupo II) não apresentaram edema pós-cirúrgico imediato e mantiveram o grau de repleção e o grau de consistência vascular semelhantes aos padrões da jugular no pré-operatório. $\mathrm{O}$ calibre do enxerto de VJEHe, por ter sido equivalente ao calibre da jugular receptora, evitou a estase sangüínea e a hipertensão local. A técnica de anastomose término-terminal empregada nos eqüinos desse grupo foi outro fator de influência, possivelmente por acarretar menor distúrbio ao fluxo sangüíneo. De acordo com Slauson e Cooper (1990), quanto menor o distúrbio laminar do fluxo sangüíneo, menor é o estímulo para a 
ativação dos fatores da coagulação. Os eqüinos que tiveram o segmento enxertado obliterado por trombos, durante o período de observação pósoperatório, desenvolveram tromboflebite na jugular cranial ao enxerto, com características semelhantes as dos eqüinos do grupo I. Essas observações comparam-se às de Traub-Dargatz e Dargatz (1994), para as quais os trombos podem induzir a inflamação na parede dos vasos, sendo rara a ocorrência de trombose sem inflamação.

A avaliação clínica por meio da compressão digital, além da simplicidade na aplicação, provou ser eficiente para verificar se os enxertos mantinham-se funcionais. Os enxertos considerados patentes apresentavam o ingurgitamento da jugular sempre que se fazia a compressão digital no período pós-operatório. A confirmação da patência desses enxertos sucedeu-se pelos exames ecográficos e pela observação macroscópica do lume vascular por ocasião da colheita do material para exames histológicos.

Os eritrogramas realizados no pré-operatório encontravam-se dentro ou muito próximos dos limites fisiológicos. Segundo Coles (1984), os valores da hematimetria variam entre 5,5$9,5 \times 10^{6} / \mu 1$ e do volume globular entre $24-44 \%$. A temporária redução na hematimetria ocorrida aos 10 dias do pós-operatório pode ser explicada pelo estresse cirúrgico e terapia anticoagulante com heparina (Moore e Hinchcliff, 1994; Lassen e Swardson, 1995). Os 30 dias de pós-operatório caracterizam-se pela recuperação do quadro hematológico por efeito da alimentação balanceada, recuperação clínica da agressão cirúrgica e interrupção da terapia pós-operatória.

Os valores leucocitários no pré-operatório mantiveram-se dentro dos limites fisiológicos, que segundo Coles (1984) e Lassen e Swardson

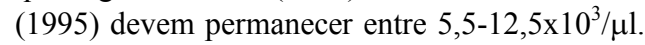
Pelos leucogramas, não foram evidenciadas alterações indicativas de processo inflamatório intenso, o que sugeriu boa tolerância aos enxertos pelo sistema celular de defesa dos eqüinos.

Os valores aumentados do fibrinogênio e das proteínas plasmáticas nos exames pré-operatórios podem ser atribuídos ao estado nutricional e hidroeletrolítico dos eqüinos, como considerou Fraser (1991). A razão entre PT/FB confirma a hiperfibrinogenemia desses eqüinos, uma vez que de acordo com Coles (1984) e Lassen e Swardson (1995), as concentrações de proteínas plasmáticas e de fibrinogênio sofrem interferência do estado hídrico, ao contrário da razão entre $\mathrm{PT} / \mathrm{FB}$, que não está sujeita a essa interferência. Os exames pós-operatórios evidenciaram o retorno aos valores fisiológicos.

Em um eqüino (IIf), verificou-se processo inflamatório na região do enxerto e aumento gradual dos níveis sangüíneos de fibrinogênio, mantidos dentro dos limites fisiológicos. A ausência de contaminação, nesse caso, foi um fator relevante para a não ocorrência de hiperfibrinogenemia, já que esse processo é freqüentemente verificado em eqüinos que apresentam tromboflebite séptica (Gardner et al., 1991).

Nos demais eqüinos, os enxertos vasculares conservados de ACCHo e VJEHe não induziram um processo inflamatório anormal e foram bem tolerados pelo organismo.

A escolha do diâmetro do enxerto implantado baseou-se no exame ultra-sonográfico préoperatório, optando-se pelo enxerto de VJEHe com o diâmetro mais próximo da jugular receptora. Para evitar o colapso do vaso pela pressão exercida no transdutor durante os exames, aplicou-se compressão digital no terço caudal da jugular, promovendo seu ingurgitamento, conforme sugerido por Dornbusch et al. (2000). A principal dificuldade encontrada para a tomada dos dados deveu-se à utilização do transdutor setorial, que emitiu com nitidez as imagens ecogênicas dos tecidos profundos, localizados abaixo da jugular, dificultando as imagens dos tecidos localizados superficialmente. Por esse motivo, nos eqüinos do grupo II foi utilizado um aparelho de ultrasom com transdutor $7,5 \mathrm{MHz}$ linear, que apresentou melhor qualidade de imagem dos tecidos subcutâneos superficiais, facilitando a visualização das paredes e lume vascular.

Ocorreram pequenos trombos próximos às válvulas dos enxertos que se mantiveram patentes durante o período pós-operatório, compatíveis com as observações de Slauson e Cooper (1990) e Cotran et al. (1994), os quais citaram as áreas de turbulências e a perda do fluxo laminar como propensas à formação de 
trombos, considerando que as válvulas das veias promoveram tais distúrbios de fluxo na passagem do sangue pelo enxerto de VJEHe.

As imagens ecogênicas dos trombos, observadas na jugular cranial e nos enxertos VJEHe, mostraram-se conforme citação de Gardner et al. (1991), os quais identificaram, ultrasonograficamente, a trombose como uma massa ecogênica uniforme, com amplitude baixa e média dos ecos, no interior da veia. Não foram observadas imagens de áreas hiperecóicas com presença de sombra acústica, que, em geral, correspondem à formação de gás dentro do trombo, sugerindo infecção anaeróbica (Marr e Reef, 1995). A ecogenicidade dos trombos aumentou com a sua organização, observação também citada por Dornbusch et al. (2000), permitindo a diferenciação das linhas de Zahn, que são, segundo Slauson e Cooper (1990), zonas alternadas de deposição de plaquetas e fibrina intercaladas com sangue, formando interfaces.

Principalmente nos eqüinos do grupo I, a tromboflebite, que se desenvolveu no segmento cranial da jugular, apresentou os sinais clínicos relacionados à afecção vascular, com aumento de temperatura e distensão ao longo do seu curso, consistência firme, espessura aumentada e sensibilidade à palpação, conforme descritos por outros autores (Deem, 1981; Bayly e Vale, 1982; Gardner e Donawick, 1992).

Todos os eqüinos apresentaram o enxerto envolvido por tecido de granulação. Nos eqüinos do grupo I, o tecido era mais exuberante que nos do grupo II, com exceção do eqüino IIe, que mostrou intensa formação de tecido fibroso envolvendo o enxerto. Essa reação é considerada normal, pois, de acordo com Anderson et al. (1996), todo implante interage, em alguma extensão, com o tecido no qual ele é implantado, e a presença de células mononucleares, incluindo linfócitos e macrófagos, deve ser considerada normal na inflamação crônica, juntamente com o desenvolvimento de tecido de granulação como resposta cicatricial normal aos biomateriais implantados.

O estudo da reação inflamatória concentrou-se nos sítios de anastomose, pois foi evidenciada maior intensidade inflamatória nesses locais. Muitas vezes, neles havia focos de necrose na túnica média e no endotélio, adjacentes às suturas. Esses mesmos achados foram descritos por Kruavit et al. (1987), ao estudarem os sítios de anastomose de enxertos de veia autógena em artérias de coelhos.

Houve reação granulomatosa com presença de células gigantes ao redor do material de sutura e com presença de tecido de granulação parcialmente organizado nas paredes dos vasos, aspecto relatado por Kruavit et al. (1987). A reação granulomatosa foi intensa, semelhante à observada por Kruavit et al. (1987). O processo foi encontrado no final do período de observação pós-operatório, associado com áreas de calcificação distrófica próximo às suturas.

Além da importância da análise do grau de reação inflamatória quanto à aceitação ou rejeição do tecido e fios utilizados, deve-se destacar, ainda, sua participação na indução da trombogênese. De acordo com Courtney e Forbes (1994), seguindo a adesão leucocitária, ocorre a ativação de funções celulares com síntese protéica e produção de radicais livres, eicosanóides, cininas e outros mediadores que podem induzir a ativação plaquetária.

Os processos inflamatórios, granulomatosos e trombogênicos, quando somados, manifestaramse como fatores suficientes para interferirem no diâmetro luminal dos enxertos empregados durante $\mathrm{o}$ experimento.

A turbulência do fluxo sangüíneo promovida pelo bypass altera o fluxo laminar, lançando as plaquetas contra o endotélio, permitindo adesão e agregação plaquetárias (Wurzinger, 1990). Como conseqüência, podem formar-se trombos oclusivos como aqueles observados nos animais do grupo I.

Nos eqüinos enxertados com VJEHe (grupo II), com o diâmetro semelhante ao vaso receptor, houve menor efeito espoliativo sobre as plaquetas e menor índice de trombos oclusivos totais na região enxertada, evidenciando a importância dos efeitos hemodinâmicos citados por Slauson e Cooper (1990) e Cotran et al. (1994). Os trombos analisados estavam organizados e permaneceram aderidos à camada íntima danificada do vaso, interferindo, muitas vezes, em sua patência. Essas observações foram também verificadas por Kruavit et al. (1987). 


\section{CONCLUSÕES}

Com base nos resultados pode-se concluir que os enxertos de ACCHo e VJEHe são compatíveis quando implantados nos eqüinos, por não estimularem o processo inflamatório acentuado, indicativo de rejeição. A utilização da $\mathrm{ACCHo,}$ conservada em glicerina, na técnica de bypass, para a restauração do fluxo da jugular em eqüinos, apresenta alta incidência na formação de trombos, principalmente na jugular cranial aos tecidos enxertados. A VJEHe, conservada em glicerina, pode ser utilizada como substituto segmentar da jugular eqüina, desde que haja semelhança entre os diâmetros vasculares.

\section{REFERÊNCIAS BIBLIOGRÁFICAS}

ANDERSON, J.M.; GRISTINA, A.G.; HANSON, S.R. et al. Host reactions to biomaterials and their evaluation. In: RATNER, B.D., HOFFMANN, A.S., SCHOEN, F.J. et al. Biomaterials science: an introduction to materials in medicine. San Diego: Academic, 1996. Cap. 4, p.165-214.

ARCHIBALD, J.; HOLT, J.C.; SOKOLOVSKY, V. Vascular injuries: technics fir vascular surgery. Modern Vet. Pract., v.61, p.35-39, 1980.

BAYLY, W.M.; VALE, B.H. Intravenous catheterization and associated problems in the horse. Cont. Educ. Art., v.4, p.227-237, 1982.

COLES, E.H. Patologia clínica veterinária. 3.ed. São Paulo: Manole, 1984. 566p.

COTRAN, R.S.; KUMAR, V.; ROBBINS, S.L. Pathologic basis of diseases. 5.ed. Philadelphia: Saunders, 1994. P.93-121.

COURTNEY, J.M.; FORBES, C.D. Thrombosis on foreign surfaces. Br. Med. Bull., v.50, p.966-981, 1994.

DEEM, D. A. Complications associated with the use of intravenous catheters in large animals. California Vet., v.6, p.19-23, 1981.

DORNBUSCH, P.T.; HUSSNI, C.A.; THOMASSIAN, A. et al. Tromboflebite jugular nos eqüinos. Rev. Educ. Cont. CRMV-SP, v.3, p.47-53, 2000.

FRASER, C.M. Manual Merk de veterinária: um manual de diagnóstico, tratamento, prevenção e controle de doenças para o veterinário. 6.ed. São Paulo: Roca, 1991. 1803p.

GARDNER, S.Y.; DONAWICK, W.J. Jugular vein thrombophlebitis. In: ROBINSON, N.E. Current therapy in equine medicine. 3.ed. Philadelphia: Saunders, 1992. P.406-408

GARDNER, S.Y.; REEF, V.B.; SPENCER, P.A. Ultrasonographic evaluation of horses with thrombophlebitis of the jugular vein: 46 cases (19851988). J. Am. Vet. Med. Assoc., v.199, p.370-373, 1991.

HAY, C.W. Equine intravenous catheterisation. Equine Vet. Educ., v.4, p.319-323, 1992.

HAY, W.P. Vascular reconstruction: are we ready for the challenge? Equine Vet. J., v.30, p.178-179, 1998.

KRUAVIT, A. M. D.; FLETCHER, C.D.M.; MCKEE, P.H. et al. Experimental microvascular autogenous vein grafts for arterial defects: a study of anastomotic sites. Microsurgery, v.8, p.201-207, 1987.

LASSEN, E.D.; SWARDSON, C.J. Hematology and hemostasis in the horse: normal functions and common abnormalities. Vet. Clin. North Am.: Equine Pract., v.11, p.351-389, 1995.

MARR, C.M.; REEF, V.B. Disturbances of flow. In: KOBLUK, C.N.; AMES, T.R.; GEOR, R.J. The horse: diseases and clinical management. Philadelphia: Saunders, 1995. Cap.10, p.157-184.

MOORE, B.R.; HINCHCLIFF, K.W. Heparin: a review of its pharmacology end therapeutic use in horses. J. Vet. Int. Med., v.8, p.26-35, 1994.

RIJKENHUIZEN, A.B.M.; VAN SWIETEN, H.A. Reconstruction of the jugular vein in horses with post thrombophebitis stenosis using saphenous vein graft. Equine. Vet. J., v.30, p.236-239, 1998.

SLAUSON, D.O.; COOPER, B.J. Mechanism of disease. A textbook of comparative general pathology. 2.ed. Baltimore: Willians \& Wilkins, 1990. Cap.3, p.79-222.

SPEIRS, V.C. Exame clínico de eqüinos. Porto Alegre: Artmed, 1999. Cap.11, p.269-306.

SPURLOCK, S.L.; SPURLOCK, G.H. Risk factors of catheter related complications. Contin. Educ. Art., v.12, p.241-246, 1990.

STASHAK, T.S. Plastic and reconstructive surgery. In: JENNINGS, P.B. The practice of large animal surgery, 1984. V.1, cap.12, p.277-294.

TRAUB-DARGATZ, J.L., DARGATZ, D.A. A retrospective study of vein thrombosis in horses treated with intravenous fluids in a veterinary teaching hospital. J. Vet. Int. Med., v.8, p.264-266, 1994.

USER'S guide: statistics. Cary, NC: SAS Institute, 1997.

WURZINGER, L.J. Histophysiology of the circulating platelet. Berlin: Universitãtsdruckerei StürtzAG, 1990. $96 \mathrm{p}$. 